\title{
Economic Load Dispatch - A Comparative Study on Heuristic Optimization Techniques With an Improved Coordinated Aggregation-Based PSO
}

Vlachogiannis, loannis (John); Lee, KY

Published in:

IEEE Transactions on Power Systems

Link to article, DOI:

10.1109/TPWRS.2009.2016524

Publication date:

2009

Document Version

Publisher's PDF, also known as Version of record

Link back to DTU Orbit

Citation (APA):

Vlachogiannis, I., \& Lee, KY. (2009). Economic Load Dispatch - A Comparative Study on Heuristic Optimization Techniques With an Improved Coordinated Aggregation-Based PSO. IEEE Transactions on Power Systems, 24(2), 991-1001. https://doi.org/10.1109/TPWRS.2009.2016524

\section{General rights}

Copyright and moral rights for the publications made accessible in the public portal are retained by the authors and/or other copyright owners and it is a condition of accessing publications that users recognise and abide by the legal requirements associated with these rights.

- Users may download and print one copy of any publication from the public portal for the purpose of private study or research.

- You may not further distribute the material or use it for any profit-making activity or commercial gain

- You may freely distribute the URL identifying the publication in the public portal 


\title{
Economic Load Dispatch-A Comparative Study on Heuristic Optimization Techniques With an Improved Coordinated Aggregation-Based PSO
}

\author{
John G. Vlachogiannis and Kwang Y. Lee, Life Fellow, IEEE
}

\begin{abstract}
In this paper an improved coordinated aggregation-based particle swarm optimization (ICA-PSO) algorithm is introduced for solving the optimal economic load dispatch (ELD) problem in power systems. In the ICA-PSO algorithm each particle in the swarm retains a memory of its best position ever encountered, and is attracted only by other particles with better achievements than its own with the exception of the particle with the best achievement, which moves randomly. Moreover, the population size is increased adaptively, the number of search intervals for the particles is selected adaptively and the particles search the decision space with accuracy up to two digit points resulting in the improved convergence of the process. The ICA-PSO algorithm is tested on a number of power systems, including the systems with 6 , 13,15 , and 40 generating units, the island power system of Crete in Greece and the Hellenic bulk power system, and is compared with other state-of-the-art heuristic optimization techniques (HOTs), demonstrating improved performance over them.
\end{abstract}

Index Terms-Adaptive velocity limits, coordinated aggregation, economic dispatch, heuristic optimization techniques, nonsmooth cost functions, particle swarm optimization.

\section{INTRODUCTION}

I $\mathrm{N}$ the electric power supply systems, there exist a wide range of problems involving optimization processes. Among them, the power system scheduling is one of the most important problems in the operation and management [1].

Recently, modern meta-heuristic algorithms are considered as effective tools for nonlinear optimization problems with applications to power systems scheduling, e.g., economic load dispatch (ELD) [2]-[26]. The algorithms do not require that the objective functions and the constraints have to be differentiable and continuous. A particle swarm optimization (PSO) is such an algorithm that can be applied to nonlinear optimization problems.

PSO has been developed from the simulation of simplified social systems such as bird flocking and fish schooling. In general, swarm behavior can be modeled with a few simple information rules. The decision process of particles in the swarm takes into

Manuscript received September 02, 2008; revised November 25, 2008. First published April 10, 2009; current version published April 22, 2009. Paper no. TPWRS-00681-2008.

J. G. Vlachogiannis is with the Department of Electrical Engineering, Technical University of Denmark, Kgs. Lyngby DK-2800, Denmark (e-mail: iv@elektro.dtu.dk).

K. Y. Lee is with the Department of Electrical and Computer Engineering, Baylor University, Waco, TX 76798-7356 USA (e-mail: Kwang_Y_Lee@baylor.edu)

Digital Object Identifier 10.1109/TPWRS.2009.2016524 account two important operators. The first one is their own experience (cognitive operator); that is, they have tried the choices and know which state has been better so far, and they know how good it was. The second one is other particles' experiences (social operator); that is, they have knowledge of how the other particles around them have performed [1]. Unlike other heuristics optimization techniques (HOTs) such as genetic algorithm (GA), PSO has a flexible and well-balanced mechanism to enhance and adapt to the global and local exploration and exploitation abilities within a short calculation time. Since PSO seems to be sensitive to the tuning of its parameters, many researches are still in progress in regulating these.

Recently, the coordinated aggregation based PSO (CA-PSO) was introduced for optimal steady-state performance of power systems [27]. The main idea of CA-PSO is based on the fact that the achievement of each particle is distributed in the entire swarm. At each iterative cycle, each particle updates its velocity taking into account the differences between its position and the positions of better achieving particles. These differences play the role of coordinators as they are multiplied as weighting factors. The best particle in the swarm is excluded from this process, as it regulates its velocity randomly [27]. However, a drawback in the CA-PSO [27] is that particles do not take into account the cognitive operator and do not adaptively organize their search.

This paper focuses on the performance evaluation of a newly introduced improved coordinated aggregation-based particle swarm optimization (ICA-PSO) algorithm in the ELD problem. Specifically, ICA-PSO is produced enhancing the CA-PSO algorithm [27]. Specifically, the CA-PSO is modified with a cognitive operator in the particles, adaptively selected number of search intervals for the particles, variable population size and search accuracy for particles up to two digit points, resulting in the improved convergence of the process.

The ICA-PSO is implemented in the ELD problem. Since 2003 the ELD problem has been solved by various modern HOTs [2]-[26], and some of them have been implemented into practice [1]. The obtained results by ICA-PSO are compared with those given by other state-of-the-art HOTs on power systems with $6,13,15$, and 40 generating units, the island power system of Crete and the Hellenic bulk power system with various loads subjected to all operating constraints.

\section{Previous Works ON HOTS FOR ELD}

The state-of-the-art HOTs for ELD are presented in this section in the reverse chronological publishing order: 
1) Simulated annealing-PSO (SA-PSO): This paper proposes a new approach and coding scheme for solving economic dispatch problems in power systems through simulated annealing like particle swarm optimization [2].

2) Quantum-inspired version of the PSO using the harmonic oscillator (HQPSO): The HQPSO is inspired by the classical PSO and quantum mechanics theories, using a harmonic oscillator (HQPSO) to solve economic dispatch problems [3].

3) Self-organizing hierarchical particle swarm optimization (SOH-PSO): In the SOH-PSO the particle velocities are reinitialized whenever the population stagnates at local optima during the search [4].

4) Bacterialforaging with Nelder-Mead algorithm (BF-NM): This paper proposes a stochastic optimization approach to solve constrained economic load dispatch problem using hybrid bacterial foraging technique. In order to explore the search space for finding the local minima, the simplex algorithm called Nelder-Mead is used along with BF algorithm [5].

5) Adaptive-PSO (APSO): This paper presents a novel heuristic optimization approach to constrained ELD problems using the adaptive-variable population-PSO technique [6].

6) Uniform design with the genetic algorithm (UHGA): This paper presents an efficient method for solving the economic dispatch problem (EDP) through combination of genetic algorithm (GA), the sequential quadratic programming (SQP) technique, uniform design technique, the maximum entropy principle, simplex crossover and nonuniform mutation [7].

7) Differential evolution $(D E)$ : The DE is a classical differential evolution algorithm attempting to solve ELD problem [8].

8) Particle swarm optimization with chaotic and Gaussian approaches (PSO-CG): In the PSO-CG a Gaussian probability distribution and chaotic sequences to generate random numbers into velocity update equation are used [9].

9) Directional search genetic algorithm (DSGA): The DSGA instead of GA-searching for final best fit chromosome in the entire random search space follows a directional procedure to reach the solution. The total search space is narrowed down to single route. The DSGA is a special algorithm for ELD problem with prohibited operating zones [10].

10) Real-parameter quantum evolutionary algorithm (RQEA): The RQEA is a modern population-based probabilistic EA that integrates concepts from quantum computing for objective functions with real parameters [11].

11) Hybrid differential evolution (HDE) and self-tuning $H D E$ (STHDE): The HDE is a differential evolution algorithm where the fittest of an offspring competes one by one with that of the corresponding parent, which is different from the other evolutionary algorithms (EAs). The STHDE utilizes the concept of the $1 / 5$ success rule of evolutionary strategies in the original HDE to accelerate the search for the global optimum [12].
12) Artificial immune system (AIS): This paper presents a novel optimization approach to constrained ELD problem using artificial immune system. The approach utilizes the clonal selection principle and evolutionary approach wherein cloning of antibodies is performed followed by hypermutation [13].

13) Variable scaling hybrid differential evolution (VSHDE): The VSHDE is an HDE with nonlinear scaling factor [14].

14) New particle swarm optimization with local random search (NPSO-LRS): The NPSO-LRS uses the classical PSO splitting up the cognitive operator into best and worst memories integrating with simple local random searches [15].

15) Improved genetic algorithm with multiplier updating (IGAMU): The IGAMU integrates an improved evolutionary direction operator and a migrating operator to avoid deforming the augmented Lagrange function [16].

16) Differential evolution combination with sequential quadratic programming method (DEC-SQP): The DEC-SQP combines the differential evolution algorithm with the generator of chaos sequences and sequential quadratic programming technique [17].

17) Evolutionary strategy optimization (ESO): The ESO is based on classical evolutionary strategy $(\mu+\lambda)$-ES paradigm, considering Gaussian mutation operator [18], [19].

18) Taguchi method (TM): The Taguchi method involves the use of orthogonal arrays in estimating the gradient of the cost function and has been widely used in experimental designs for problems with multiple parameters where the optimization of a cost function is required [20].

19) Modified particle swarm optimization (MPSO): The MPSO introduces a mechanism in classical PSO to deal with the equality and inequality constraints in the ELD. A constraint treatment mechanism is devised in such a way that the dynamic process inherent in the conventional PSO is preserved. Moreover, a dynamic search-space reduction strategy is devised to accelerate the optimization process [21].

20) Evolutionary programming algorithm with non-linear scaling factor (EP-NSF): In the proposed EP-NSF algorithm, mutation changes nonlinearly with respect to the number of generations avoiding premature condition [22].

21) Hybrid particle swarm optimization with sequential quadratic programming (PSO-SQP): The PSO-SQP combines the PSO with the conventional sequential quadratic programming technique [23].

22) Particle swarm optimization (PSO): The classical PSO algorithm is introduced as a solution method of ELD [24].

23) Real GA: The developed real-coded GA is based on a floating-point coding scheme observing transmission line power-flow limits [25].

24) Improved fast evolutionary programming (IFEP): The proposed IFEP algorithm uses both Gaussian and Cauchy mutations to create offspring from the same parent and the better ones are chosen for next generation [26].

\section{ECONOMIC LOAD DISPATCH}

The main purpose of this paper is the performance evaluation of the proposed ICA-PSO in optimal ELD. Therefore, the 
ICA-PSO algorithm is tested and compared with other state-ofthe-art HOTs on this problem. Thus, a clear picture of the effectiveness of the proposed ICA-PSO is given. The objective of the ELD problem is to minimize the total fuel cost at thermal power plants subjected to the operating constraints of a power system. Therefore, it can be formulated mathematically with an objective function and two constraints (equality and inequality).

\section{A. Equality Constraint}

In the power balance criterion, the equality constraint should be satisfied as

$$
\sum_{i=1}^{N_{G}} P_{i}-P_{D}-P_{\text {Loss }}=0
$$

where $N_{G}$ represents the total number of generators. So, the total generated real power should be the same with the total load demand $P_{D}$ plus transmission losses $P_{\text {Loss }}$ of the system. The $P_{\text {Loss }}$ are calculated using power flows coefficients $B_{i j}$ by the following formula:

$$
P_{\mathrm{Loss}}=\sum_{i} \sum_{j} P_{i} B_{i j} P_{j}+\sum_{i} B_{0 i} P_{i}+B_{00}
$$

\section{B. Inequality Constraints}

The real power output $P_{i}$ of each generator- $i$ should lie between maximum $P_{i, \max }$ and minimum $P_{i, \min }$ limits represented by

$$
P_{i, \min } \leq P_{i} \leq P_{i, \max }
$$

Also generators have certain prohibited operating zones due to steam valve or vibration in shaft bearings

$$
\begin{aligned}
P_{i, \min } & \leq P_{i} \leq P_{i}^{\text {lower }_{1}} \text { or } \\
P_{i}^{\text {upper }_{j-1}} & \leq P_{i} \leq P_{i}^{\text {lower }_{j}} j=2, \ldots, \mathrm{np}_{i} \text { or } \\
P_{i}^{\text {upper }_{\mathrm{np}_{i}}} & \leq P_{i} \leq P_{i, \max }
\end{aligned}
$$

where $P_{i}^{\text {lower }_{j}}$ and $P_{i}^{\text {upper }_{j-1}}$ are, respectively, the lower and upper bounds of prohibited zone $j$ of generator- $i$ and $\mathrm{np}_{i}$ is the number of prohibited zones in generator- $i$.

\section{Fitness Function}

The total fuel cost function (in $\$ / \mathrm{h}$ or $€ / \mathrm{h}$ ) addressing the valve-point loadings of generating units to be minimized is given by

$$
\begin{aligned}
\min _{P_{i}} F_{C} & =\sum_{i=1}^{N_{G}} F_{i} \\
& =\sum_{i=1}^{N_{G}}\left(\alpha_{i}+b_{i} P_{i}+c_{i} P_{i}^{2}+\left|e_{i} \sin \left(f_{i}\left(P_{i, \min }-P_{i}\right)\right)\right|\right)
\end{aligned}
$$

where $a_{i}, b_{i}, c_{i}, e_{i}, f_{i}$ are the fuel cost coefficients of generating unit- $i$.

In order to speed up the convergence of iteration procedure, the evaluation value is normalized into the range between 0 and 0.5 . Specifically, the evaluation function $f$ is adopted as in [24]

$$
f=\frac{1}{F_{C, \text { Norm }}+F_{L, \text { Norm }}}
$$

where

$$
\begin{aligned}
& F_{C, \text { Norm }}=1+\frac{F_{C}-F_{\min }}{F_{\max }-F_{\min }} \\
& F_{L, \text { Norm }}=1+\left(\sum_{i=1}^{N_{G}} P_{i}-P_{D}-P_{\text {Loss }}\right)^{2} .
\end{aligned}
$$

Here, $F_{\max }$ and $F_{\min }$ are the total cost of generating units at their maximum and minimum limits, respectively, calculated at the initial population.

Evaluation function (6) is the reciprocal of power balance constraint and the generation cost function as in (1) and (5). This implies that if the values of (7) and (8) of a particle are small, then its evaluation value (6) would be large.

In order to limit the evaluation value of each particle of the swarm within a feasible range, before estimating the evaluation value of a particle (6), the generation power output must satisfy the constraints in (4). If a particle satisfies all constraints, then it is a feasible particle and (7) has a small value. Otherwise, the value (7) of the particle is penalized with a very large positive constant.

\section{IMPROVEd COORDINATED AGGREGATION-BASEd PSO}

The coordinated aggregation is a new operator introduced recently in the swarm, where each particle moves considering only the positions of particles with better achievements than its own with the exception of the best particle, which moves randomly. The coordinated aggregation can be considered as a type of active aggregation where particles are attracted only by places with the most food. Specifically, at each iterative cycle- $t$ of ICAPSO, each particle- $j$ with better achievement than particle- $i$ regulates the velocity of the second. The velocity of particle $-i$ is adapted by means of coordinators multiplied by weighting factors. The differences between the positions of particles- $j$ and the position of particle- $i, S_{j}(t)-S_{i}(t)$, are defined as coordinators of particle- $i$ velocity. The ratios of differences between the achievement of particle- $i, \quad f\left(S_{i}\right)$, and the better achievements by particles- $j, \quad f\left(S_{j}\right)$, to the sum of all these differences are the weighting factors $w_{i j}(t)$ of the coordinators

$$
w_{i j}=\frac{f\left(S_{j}\right)-f\left(S_{i}\right)}{\sum_{l}\left(f\left(S_{l}\right)-f\left(S_{i}\right)\right)} \quad j, l \in T_{i}
$$

where $T_{i}$ represents the set of particles $-j$ with better achievement than particle- $i$.

Also, the ICA-PSO considers the following additional concepts and techniques. 
1) The cognitive operator of the particles (the ability of the particles to retain a memory of its best position ever achieved) for better exploitation of the search space.

2) He adaptively selected number of search intervals for the particles and the variable population size, resulting in the improved convergence of the process for better exploration of the search space. Specifically, the maximum velocities are constricted in a small number of search intervals, $\mathrm{Nr}$, in the search space for better balance between exploration and exploitation. A small $\mathrm{Nr}$ facilitates global exploration (searching new areas), while a large one tends to facilitate local exploration (fine tuning of the current search area) [see (13)]. A suitable value for the $\mathrm{Nr}$ usually provides balance between global and local exploration abilities and consequently results in a reduction of the number of iterations required to locate the optimum solution [27]. In the ICA-PSO, the number of search intervals $(\mathrm{Nr})$ is selected adaptively during the iterative process in the areas with the rate of search in (10) at the bottom of the page, where $n_{\text {Allow }}, n_{\text {Emer }}$ and $n_{\text {Fail }}$ are, respectively, the limits on the allowed, emergency and failed number of iterations $(t) ; \mathrm{Nr}_{\min , N}, \mathrm{Nr}_{\max , N}$ are the limits of $\mathrm{Nr}$ in the area of normal search rate; $\mathrm{Nr}_{\min , I}, \mathrm{Nr}_{\text {max }, I}$ are the limits of $\mathrm{Nr}$ in the area of intensive search rate, and $\mathrm{Nr}_{\min , S}, \mathrm{Nr}_{\text {max }, S}$ are the limits of $\mathrm{Nr}$ in the area of scrutiny. Moreover, if no improvement in the global best achievement is observed for $n_{\text {Fail }}$ number of iterations the population size is increased by $15 \%$.

3) The particles search the decision space with accuracy up to two decimal points. So, they avoid many local minima, premature convergence and explore/exploit better and faster only three surfaces ( $0-2$ digit points) of the decision space.

The steps of ICA-PSO for ELD are listed in the following.

Step 1) Initialization: Generate $N$-particles. For each particle- $i$ choose initial position vector $S_{i}(0)$ (initial vector of generators' real power outputs) randomly and set it as best position $P_{i}(0)$ of particle- $i$. Calculate its initial achievement $f\left(S_{i}(0)\right)$ using the evaluation function (6) and find the maximum $\left(f_{g}(0)=\right.$ $\left.\max _{i} f\left(S_{i}(0)\right)\right)$ called the global best achievement. Then, particles update their positions (generators' real power outputs) in accordance with the following steps.

Step 2) Swarm's manipulation: The particles, except the best of them regulate their velocities in accordance with the equation

$V_{i}(t+1)=\operatorname{rand}_{i} \cdot\left(V_{i}(t)+c \cdot\left(P_{i}-S_{i}(t)\right)\right)$
$\quad+\sum_{j} \operatorname{rand}_{j} \cdot w_{i j}(t) \cdot\left(S_{j}(t)-S_{i}(t)\right), \quad j \in T_{i}$ where $i=1,2, \ldots, N ; c$ is the cognitive parameter; $P_{i}$ is the best position of the particle- $i$ it ever encountered; the random parameters rand $_{i}$ and rand $_{j}$ are used to maintain the diversity of the population and are respectively uniformly distributed within the ranges $[0.999,1]$ and $[0,1] ; w_{i j}(t)$ are the weighting factors of the coordinators (9).

Step 3) Best particle's manipulation: The best particle in the swarm updates its velocity using a random coordinator calculated between its position and the position of a randomly chosen particle in the swarm.

Step 4) Velocity bounds' oscillations: Check if the bounds of velocities are enforced, (12), (13). If the bounds are violated then they are replaced by the respective limits. The velocities of the $i$ th particle in the $n$-dimensional decision space are limited by

$$
\left[-V_{i}^{\max }, V_{i}^{\max }\right]
$$

where the maximum velocity in the $l$-th dimension (generator- $l$ ) of the search space is proposed as

$v_{i, l}^{\max }=\frac{s_{i, l}^{\max }-s_{i, l}^{\min }}{\mathrm{Nr}}, \quad(i=1,2, \ldots, n)$

where $s_{i, l}^{\min }$ and $s_{i, l}^{\max }$ are the limits in the $l$-dimension of the search space [limits of real power outputs of generator- $l,(3)]$ and $\mathrm{Nr}$ is the chosen number of the search intervals (10). Normally, choose a random integer number in the range of $\left[\mathrm{Nr}_{\min , N}, \mathrm{Nr}_{\max , N}\right]$.

Step 5) Position update: The positions of particles (generators' real power outputs) are updated on the basis of

$$
S_{i}(t+1)=S_{i}(t)+V_{i}(t+1) .
$$

Step 6) Position limits: Check if the limits of particles' positions (generators prohibited operating zones) are enforced (4). If any of the limits are violated then a high penalty is added in (7) and the corresponding number of search interval (10) is set at the lowest value $\mathrm{Nr}=\mathrm{Nr}_{\min , N}$.

Step 7) Evaluation: Calculate the achievement $f\left(S_{i}(t)\right)$ of each particle- $i$ using the evaluation function (6) and calculate the maximum one among them.

Step 8) Update search intervals and population size: If no improvement in the global best is achieved for $t$ number of iterations with: $a$ ) $n_{\text {Allow }}<t \leq n_{\text {Emer }}$ choose a random integer number of search intervals in the range of $\left.\left[\mathrm{Nr}_{\min , I}, \mathrm{Nr}_{\max , I}\right], b\right) n_{\text {Emer }}<t<$

$$
\mathrm{Nr} \in\left\{\begin{array}{l}
\text { Normal }:\left[\mathrm{Nr}_{\min , N}, \mathrm{Nr}_{\text {max }, N}\right] \text { if } t \leq n_{\text {Allow }} \\
\text { Intensive }:\left[\mathrm{Nr}_{\text {min }, I}, \mathrm{Nr}_{\text {max }, I}\right] \text { if } n_{\text {Allow }}<t \leq n_{\text {Emer }} \\
\text { Scrutiny }:\left[\mathrm{Nr}_{\min , S}, \mathrm{Nr}_{\text {max }, S}\right] \text { if } n_{\text {Emer }}<t<n_{\text {Fail }}
\end{array}\right.
$$


$n_{\text {Fail }}$ choose a random integer number of search intervals in the range of $\left.\left[\mathrm{Nr}_{\min , S}, \mathrm{Nr}_{\max , S}\right], c\right) t \geq$ $\mathrm{n}_{\text {Fail }}$ increase the population size every $n_{\text {Allow }}+$ $n_{\text {Emer }}+n_{\text {Fail }}$ iterations by $15 \%$ up to $90 \%$ of the initial size.

Step 9) Stopping criteria: The ICA-PSO algorithm will be terminated if the maximum number of allowed iterations is achieved (iter max $_{1000)}$. If the stopping criteria are not satisfied, go to Step 2.

Step 10) Global optimal solution: Choose the optimal solution as the global best achievement

$$
S_{g}=\arg \max f_{g}\left(S_{g}\right)
$$

\section{Performance Evaluation}

To assess the efficiency of the proposed ICA-PSO, the following seven case studies of ELD with various loads are applied.

Case 1) Six-generating units of IEEE 30-bus system. In this application the obtained results are compared with those given by EP-NSF [22].

Case 2) 13-generating units. In this application the results are compared with those given by SA-PSO [2], HQPSO [3], BF-NM [5], UHGA [7], DE [8], RQEA [11], HDE and STHDE [12], IGAMU [16], DEC-SQP [17], ESO [18], [19], PSO-SQP [23], and IFEP [26].

Case 3) 15-generating units. In this application the results are compared with those given by SA-PSO [2], SOH-PSO [4], BF-NM [5], APSO [6], DE [8], PSO-CG [9], DSGA [10], AIS [13], HDE and VSHDE [14], IGAMU [16], ESO [18], [19], and PSO [24].

Case 4) 40-generating units. In this application the results are compared with those given by SA-PSO [2], SOH-PSO [4], BF-NM [5], UHGA [7], DE [8], HDE and STHDE [12], NPSO-LRS [15], IGAMU [16], DEC-SQP [17], ESO [18], [19], TM [20], MPSO [21], PSO-SQP [23], and IFEP [26].

Case 5) Autonomous power system of island of Crete, Greece. In this application the results are compared with those given by Real GA [25].

Case 6) Hellenic bulk power system. The version with 32 combined cycle co-generation plant (CCCP) generating units is considered.

Case 7) A six-generating units with prohibited operating zones considering power loss. In this application the obtained results are compared with those given by SA-PSO [2], BF-NM [5], APSO [6], DE [8], AIS [13], NPSO-LRS [15], ESO [18], [19], and PSO [24].

The performance of ICA-PSO is quite sensitive to the various parameter settings. Tuning of parameters is essential in all PSO based methods. Based on empirical studies on a number of mathematical benchmarks, we [27], [28] have reported the best range of variation for cognitive and social parameters, inertia weighting factor, number of search intervals, and population size. This paper further explores the best range of newly
TABLE I

PARAMETERS OF ICA-PSO

\begin{tabular}{cccccccc}
\hline Parameter & Case & Case & Case & Case & Case & Case & Case \\
& $\mathbf{1}$ & $\mathbf{2}$ & $\mathbf{3}$ & $\mathbf{4}$ & $\mathbf{5}$ & $\mathbf{6}$ & $\mathbf{7}$ \\
\hline $\boldsymbol{n}_{\text {Allow }}$ & 10 & 10 & 10 & 10 & 10 & 10 & 10 \\
$\boldsymbol{n}_{\text {Emer }}$ & 20 & 20 & 20 & 20 & 20 & 20 & 20 \\
$\boldsymbol{n}_{\text {Fail }}$ & 50 & 50 & 50 & 50 & 50 & 50 & 50 \\
$\boldsymbol{N} \boldsymbol{r}_{\text {min, },}$ & 10 & 20 & 15 & 15 & 50 & 15 & 20 \\
$\boldsymbol{N} \boldsymbol{r}_{\text {max }, N}$ & 50 & 500 & 500 & 500 & 500 & 500 & 500 \\
$\boldsymbol{N} \boldsymbol{r}_{\boldsymbol{m i n}, \boldsymbol{I}}$ & 50 & 500 & 1200 & 1200 & 1200 & 500 & 500 \\
$\boldsymbol{N} \boldsymbol{r}_{\boldsymbol{m a x}, \boldsymbol{I}}$ & 150 & 1500 & 1700 & 1700 & 1700 & 1500 & 1500 \\
$\boldsymbol{N} \boldsymbol{r}_{\boldsymbol{m i n}, \boldsymbol{S}}$ & 150 & 1500 & 2500 & 4000 & 2500 & 1500 & 1500 \\
$\boldsymbol{N} \boldsymbol{r}_{\text {max }, \boldsymbol{S}}$ & 250 & 2500 & 3500 & 5000 & 3500 & 2500 & 2500 \\
$N-($ initial $)$ & 20 & 40 & 40 & 70 & 40 & 70 & 20 \\
$\boldsymbol{C}$ & 0.5 & 0.5 & 0.5 & 0.5 & 0.5 & 0.5 & 0.5 \\
\hline
\end{tabular}

TABLE II

ICA-PSO FOR SIX-GENERATING UNITS: RESULTS AND CONVERGENCE CHARACTERISTICS

\begin{tabular}{cccc}
\hline Generating units & Outputs (MW) & $\begin{array}{c}\text { Generating } \\
\text { units }\end{array}$ & $\begin{array}{c}\text { Outputs } \\
\text { (MW) }\end{array}$ \\
\hline 1 & 172.89 & 4 & 10.10 \\
2 & 51.20 & 5 & 13.48 \\
3 & 20.10 & 6 & 15.87 \\
Load demand (MW) & & 283.40 & \\
Power loss (MW) & & 0.24 & \\
Minimum cost (\$/h) & & 697.73 & \\
Mean cost (\$/h) & & 698.02 & \\
Maximum cost (\$/h) & & 700.15 & \\
Number of iterations & & 197 & \\
CPU time / per iteration & & 0.025 & \\
(sec) & &
\end{tabular}

introduced parameters in (10), where sensitivity analysis was performed with respect to the parameters: allowed, emergency and failed limits in the number of iterations; chosen limits of search intervals for the particles in the normal, intensive and scrutiny search areas; population size $(N)$; and cognitive parameter $(c)$. The stochastic parameters of ICA-PSO shown in Table I are those, which yielded best solution for each case study. They were selected after many trial runs by means of sensitivity analysis. The minimum, mean and maximum of cost functions (8) are estimated with up to 1000 iterations in 100 trials on a 1.4-GHz Pentium-IV PC.

\section{A. Case 1}

The ICA-PSO is applied to the IEEE-30 bus system with six-generating units, 41 transmission lines, four tap changing transformers, and two injected VAR sources. The total system load demand is 283.4 MW. The cost coefficients of IEEE 30-bus system are slightly modified to incorporate nonsmooth fuel cost functions as given in EP-NSF [22]. The first generating unit is a combined cycle co-generation plant (CCCP), the second generating unit has piecewise cost function, the third and fourth generators have valve point loadings, and the last two have quadratic cost functions. The ramp rate limits of generating units are also given in EP-NSF [22]. Table II shows the best dispatch solution obtained by ICA-PSO for this system. They are better than those given by EP-NSF (total minimum cost: $747.3 \$ / \mathrm{h}$ ) [22]. 
TABLE III

ICA-PSO FOR 13-GENERATING UNITS: RESULTS AND CONVERGENCE CHARACTERISTICS

\begin{tabular}{|c|c|c|c|c|}
\hline $\begin{array}{c}\text { Generating } \\
\text { units }\end{array}$ & $\begin{array}{l}\text { Outputs } \\
\text { (MW) }\end{array}$ & $\begin{array}{l}\text { Outputs (MW) } \\
\text { "Constrained" }\end{array}$ & $\begin{array}{c}\text { Outputs } \\
\text { (MW) }\end{array}$ & $\begin{array}{c}\text { Outputs } \\
\text { (MW) }\end{array}$ \\
\hline 1 & 628.32 & 628.32 & 628.32 & 628.32 \\
\hline 2 & 149.60 & 299.20 & 299.19 & 299.19 \\
\hline 3 & 222.75 & 291.90 & 294.51 & 294.51 \\
\hline 4 & 109.86 & 159.73 & 159.73 & 159.73 \\
\hline 5 & 109.86 & 159.73 & 159.73 & 159.73 \\
\hline 6 & 60.00 & 159.73 & 159.73 & 159.73 \\
\hline 7 & 109.87 & 159.73 & 159.73 & 159.73 \\
\hline 8 & 109.87 & 159.73 & 159.73 & 159.73 \\
\hline 9 & 109.87 & 159.73 & 159.73 & 159.73 \\
\hline 10 & 40.00 & 114.80 & 114.80 & 114.80 \\
\hline 11 & 40.00 & 75 & 77.40 & 116.45 \\
\hline 12 & 55.00 & 60 & 55.00 & 55.00 \\
\hline 13 & 55.00 & 92.40 & 92.40 & 92.40 \\
\hline $\begin{array}{l}\text { Load demand } \\
\text { (MW) }\end{array}$ & 1800.00 & 2520.00 & 2520.00 & 2520.00 \\
\hline $\begin{array}{l}\text { Power loss } \\
\text { (MW) }\end{array}$ & 0.0 & 0.0 & 0.0 & 39.05 \\
\hline $\begin{array}{l}\text { Minimum cost } \\
(\$ / h)\end{array}$ & 17960.37 & 24246.60 & 24168.91 & 24540.06 \\
\hline Mean cost $(\$ / h)$ & 17967.94 & 24252.65 & 24175.34 & 24561.46 \\
\hline $\begin{array}{l}\text { Maximum cost } \\
(\$ / h)\end{array}$ & 17978.14 & 24263.56 & 24184.92 & 24589.45 \\
\hline $\begin{array}{c}\text { Number of } \\
\text { iterations }\end{array}$ & 192 & 324 & 479 & 413 \\
\hline $\begin{array}{l}\text { CPU time / per } \\
\text { iteration (sec) }\end{array}$ & 0.052 & 0.052 & 0.052 & 0.052 \\
\hline
\end{tabular}

\section{B. Case 2}

In this application power system has 13-generating units. In the literature there are four different applications with load demand of the system at values of $1800 \mathrm{MW}, 2520 \mathrm{MW}$ without power loss (constrained and unconstrained cases), and 2520 MW considering power loss [2], [3], [5], [7], [8], [11], [12], [14], [16]-[19], [23], [26]. In the "constrained" case with load demand at value of $2520 \mathrm{MW}$ without power loss, the outputs of generating units 11 and 12 are fixed at $75 \mathrm{MW}$ and $60 \mathrm{MW}$, respectively. In the fourth application where power loss is considered the total power generation is $2559.05 \mathrm{MW}$, namely there is a power loss of $39.05 \mathrm{MW}$. In this case, the HDE and STHDE [12] achieve power loss of 39.15 MW and 44.33 MW, respectively. Table III shows the best dispatch solution and convergence characteristics of ICA-PSO, for all cases of load demand. The results obtained by ICA-PSO are compared with those available from the literature in Table IV. The results of ICA-PSO are better than all cases except in the case of load demand at value of $2520 \mathrm{MW}$ without power loss, where RQEA [11] achieves better minimum cost.

\section{Case 3}

In this application power system has 15-generating units, where four units have prohibited operating zones. In the literature there are three applications with the load demand of 2650 MW without power loss, $2650 \mathrm{MW}$ considering power loss, and $2630 \mathrm{MW}$ considering power loss [2], [4]-[6], [8]-[10], [13], [14], [16], [18], [19], [24]. Table V shows the best dispatch solution and convergence characteristics of ICA-PSO for all
TABLE IV

Minimum GeNeration Cost ObTaINEd By DifFERENT METHODS ON 13-GENERATING UNITS SYSTEM

\begin{tabular}{ccccc}
\hline Method & $\begin{array}{c}\text { Total } \\
\text { power } \\
\mathbf{1 8 0 0} \mathbf{M W}\end{array}$ & $\begin{array}{c}\text { Total power } \\
\mathbf{2 5 2 0} \mathbf{M W} \\
\text { "Constrained" }\end{array}$ & $\begin{array}{c}\text { Total } \\
\text { power } \\
\mathbf{2 5 2 0} \mathbf{M W}\end{array}$ & $\begin{array}{c}\text { Total } \\
\text { power } \\
\mathbf{2 5 5 9 . 0 5} \\
\text { MW }\end{array}$ \\
\hline ICA-PSO & $\mathbf{1 7 9 6 0 . 3 7}$ & $\mathbf{2 4 2 4 6 . 6 0}$ & 24168.91 & $\mathbf{2 4 5 4 0 . 0 6}$ \\
SA-PSO & - & - & 24171.39 & - \\
HQPSO & 17963.95 & - & - & - \\
BF-NM & 17960.49 & - & - & - \\
UHGA & 17964.81 & - & 24172.25 & - \\
DE & 17963.83 & - & 24169.92 & - \\
RQEA & - & 24252.05 & 24164.04 & - \\
HDE & 17975.73 & - & - & 24591.76 \\
STHDE & 17963.79 & - & - & 24560.08 \\
IGAMU & - & - & 24169.97 & - \\
DEC- & 17963.94 & - & - & - \\
SQP & - & - & 24221.77 & - \\
ESO & - & 24261.05 & - & - \\
PSO-SQP & 17969.93 & - & - & - \\
IFEP & 17994.07 & & &
\end{tabular}

TABLE V

ICA-PSO FOR 15-GENERATING UNITS: RESULTS AND CONVERGENCE CHARACTERISTICS

\begin{tabular}{cccc}
\hline Generating units & \multicolumn{3}{c}{ Outputs (MW) } \\
\hline 1 & 455.00 & 455.00 & 455.00 \\
2 & 420.00 & 419.99 & 419.99 \\
3 & 130.00 & 130.00 & 130.00 \\
4 & 130.00 & 130.00 & 130.00 \\
5 & 260.00 & 260.00 & 260.00 \\
6 & 430.00 & 429.99 & 429.99 \\
7 & 465.00 & 465.00 & 465.00 \\
8 & 60.00 & 60.00 & 60.00 \\
9 & 25.00 & 27.67 & 25.00 \\
10 & 62.60 & 111.29 & 76.70 \\
11 & 80.00 & 80.00 & 80.00 \\
12 & 77.40 & 78.01 & 54.77 \\
13 & 25.00 & 25.00 & 25.00 \\
14 & 15.00 & 15.00 & 15.00 \\
15 & 15.00 & 15.00 & 15.00 \\
15 & 2650.00 & 2650.00 & 2630.00 \\
Poad demand (MW) & 0.0 & 51.95 & 11.45 \\
Minimum cost (\$/h) & 32480.91 & 33048.32 & 32393.23 \\
Mean cost (\$/h) & 32486.76 & 33060.18 & 32400.17 \\
Maximum cost (\$/h) & 32496.47 & 33078.23 & 32414.32 \\
Number of iterations & 472 & 465 & 345 \\
CPU time / per iteration (sec) & 0.058 & 0.058 & 0.058 \\
\hline
\end{tabular}

cases of load demand. The table also shows the convergence characteristics of ICA-PSO, namely the iteration number achieved, the minimum cost (best iteration), mean CPU time per iteration, and minimum, mean and maximum cost (5). The results obtained by ICA-PSO are compared with those available from the literature in Table VI. It shows that the ICA-PSO performed better than all other HOTs.

\section{Case 4}

In this application power system has 40-generating units. Total load demand of the system is $10500 \mathrm{MW}$. In the literature there are many HOTs applications in this system [2], [4], [5], 
TABLE VI

Minimum GeNeration Cost ObTaINED By DifFerent METHODS ON 15-GENERATING UNITS SYSTEM

\begin{tabular}{cccc}
\hline Method & $\begin{array}{c}\text { Total power } \\
\mathbf{2 6 5 0} \mathbf{M W}\end{array}$ & $\begin{array}{c}\text { Total power } \\
\mathbf{2 7 0 1 . 9 5} \mathbf{M W}\end{array}$ & $\begin{array}{c}\text { Total power } \\
\mathbf{2 6 4 1 . 4 4} \mathbf{M W}\end{array}$ \\
\hline ICA-PSO & $\mathbf{3 2 4 8 0 . 9 1}$ & $\mathbf{3 3 0 4 8 . 3 3}$ & $\mathbf{3 2 3 9 3 . 2 3}$ \\
SA-PSO & - & - & 32708.00 \\
SOH-PSO & - & - & 32751.39 \\
BF-NM & - & - & 32784.50 \\
APSO & - & - & 32742.77 \\
DE & - & - & 32588.86 \\
PSO-CG & & - & 32508.12 \\
DSGA & 32545.00 & - & - \\
STHDE & - & 33343.37 & - \\
AIS & - & 33282.17 & 32854.00 \\
VSHDE & - & - & - \\
IGAMU & 32506.33 & - & 32640.85 \\
ESO & 32507.67 & - & 32858.00 \\
PSO & - & &
\end{tabular}

TABLE VII

ICA-PSO FOR 40-GENERATING UNITS: RESULTS AND CONVERGENCE CHARACTERISTICS

\begin{tabular}{|c|c|c|c|}
\hline $\begin{array}{c}\text { Generating } \\
\text { units }\end{array}$ & Outputs (MW) & Generating units & Outputs (MW) \\
\hline 1 & 110.80 & 21 & 523.28 \\
\hline 2 & 110.80 & 22 & 523.28 \\
\hline 3 & 97.41 & 23 & 523.28 \\
\hline 4 & 179.74 & 24 & 523.28 \\
\hline 5 & 88.52 & 25 & 523.28 \\
\hline 6 & 140.00 & 26 & 523.28 \\
\hline 7 & 259.60 & 27 & 10.00 \\
\hline 8 & 284.60 & 28 & 10.00 \\
\hline 9 & 284.60 & 29 & 10.00 \\
\hline 10 & 130.00 & 30 & 96.39 \\
\hline 11 & 168.80 & 31 & 190.00 \\
\hline 12 & 94.00 & 32 & 190.00 \\
\hline 13 & 214.76 & 33 & 190.00 \\
\hline 14 & 394.28 & 34 & 164.82 \\
\hline 15 & 394.28 & 35 & 200.00 \\
\hline 16 & 304.52 & 36 & 200.00 \\
\hline 17 & 489.28 & 37 & 110.00 \\
\hline 18 & 489.28 & 38 & 110.00 \\
\hline 19 & 511.28 & 39 & 110.00 \\
\hline 20 & 511.28 & 40 & 511.28 \\
\hline $\begin{array}{l}\text { Load demand } \\
\text { (MW) }\end{array}$ & & 10500.00 & \\
\hline $\begin{array}{l}\text { Power loss } \\
\text { (MW) }\end{array}$ & & 0.0 & \\
\hline$\underset{(\$ / h)}{\operatorname{Minimum}} \operatorname{cost}$ & & 121413.20 & \\
\hline Mean cost $(\$ / h)$ & & 121428.14 & \\
\hline $\begin{array}{c}\text { Maximum cost } \\
(\$ / h)\end{array}$ & & 121453.56 & \\
\hline $\begin{array}{c}\text { Number of } \\
\text { iterations }\end{array}$ & & 636 & \\
\hline $\begin{array}{l}\text { CPU time / per } \\
\text { iteration (sec) }\end{array}$ & & 0.22 & \\
\hline
\end{tabular}

[7], [8], [12], [15]-[21], [23], [26]. Table VII shows the best dispatch solution and convergence characteristics of ICA-PSO. The results obtained by ICA-PSO are compared with those available from the literature in Table VIII, which shows that the performance of the ICA-PSO is exceeding in all other cases.
TABLE VIII

Minimum GENERATION COST OBTAINED By DiFFERENT METHODS ON 40-GENERATING UNITS SYSTEM

\begin{tabular}{cccc}
\hline Method & $\begin{array}{c}\text { Minimum cost } \\
(\mathbf{\$} / \mathbf{h})\end{array}$ & Method & $\begin{array}{c}\text { Minimum cost } \\
(\mathbf{\$} / \mathbf{h})\end{array}$ \\
\hline ICA-PSO & $\mathbf{1 2 1 4 1 3 . 2 0}$ & NPSO-LRS & 121664.43 \\
SA-PSO & 121430.00 & IGAMU & 121819.25 \\
SOH-PSO & 121501.14 & DEC-SQP & 121741.97 \\
BF-NM & 121423.63 & ESO & 121630.96 \\
UHGA & 121424.48 & TM & 122477.78 \\
DE & 121416.29 & MPSO & 122252.26 \\
STHDE & 123598.76 & PSO-SQP & 122094.67 \\
VSHDE & 123496.02 & IFEP & 122624.35 \\
\hline
\end{tabular}

TABLE IX

ICA-PSO FOR CRETE'S POWER SYSTEM (18-GENERATING UNITS): RESULTS AND CONVERGENCE CHARACTERISTICS

\begin{tabular}{cccc}
\hline Generating units & $\begin{array}{c}\text { Outputs } \\
(\mathbf{M W})\end{array}$ & $\begin{array}{c}\text { Generating } \\
\text { units }\end{array}$ & $\begin{array}{c}\text { Outputs } \\
\text { (MW) }\end{array}$ \\
\hline 1 & 15.00 & 10 & 12.28 \\
2 & 45.00 & 11 & 12.28 \\
3 & 25.00 & 12 & 24.00 \\
4 & 25.00 & 13 & 3.00 \\
5 & 25.00 & 14 & 34.04 \\
6 & 4.13 & 15 & 35.35 \\
7 & 4.13 & 16 & 37.00 \\
8 & 12.28 & 17 & 36.23 \\
9 & 12.28 & 18 & 3.00 \\
Load demand (MW) & & 365.00 & \\
Power loss (MW) & & 0.0 & \\
Minimum cost (\$/h) & & 25430.16 & \\
Mean cost (\$/h) & & 25440.89 & \\
Maximum cost $\mathbf{( \$ / h )}$ & & 25462.34 & \\
Number of iterations & & 315 & \\
CPU time / per & & 0.059 & \\
iteration (sec) & & &
\end{tabular}

\section{E. Case 5}

In this application the ELD problem in the autonomous power system of Greek island of Crete is solved. Two subcases are considered. In the first sub-case the system comprises of 18-generating units with quadratic (convex) cost functions, 52 buses, 66 branches, and 18 thermal units. In this subcase branch-power flow limits are considered. The data are given in [25]. Table IX shows the best dispatch solution and the convergence characteristics of ICA-PSO. The results of ICA-PSO in this version of the Crete's power system with various loads are compared with those given by Real GA [25] in Table X. The maximum power capability is $P_{G, \max }=433.22 \mathrm{MW}$. The results given by ICA-PSO are better than those given by Real GA [25]. In the second sub-case the system comprises 19-generating units with cubic (nonconvex) cost functions. In this subcase also branchpower flow limits are considered. The maximum power capability is $P_{G, \max }=490.3 \mathrm{MW}$. Total load demand of the system is $400 \mathrm{MW}$ (medium load). The technical limits and the coefficients of cost functions of 19-generating units are given in Appendix A. Table XI shows the best dispatch solution and convergence characteristics of ICA-PSO. 
TABLE X

ICA-PSO AND REAL GA FOR CRETE'S POWER SYSTEM (18-GENERATING UNITS-VARIOUS LOADS)

\begin{tabular}{ccc}
\hline $\begin{array}{c}\text { Load demand } \\
(\mathbf{M W})\end{array}$ & ICA-PSO $\mathbf{( \$ / h )}$ & Real GA (\$/h) \\
\hline $95 \% \mathrm{P}_{\mathrm{G}, \max }$ & $\mathbf{2 9 7 3 1 . 0 3}$ & 29731.05 \\
$90 \% \mathrm{P}_{\mathrm{G}, \max }$ & $\mathbf{2 7 6 5 3 . 9 2}$ & 27655.53 \\
$80 \% \mathrm{P}_{\mathrm{G}, \max }$ & $\mathbf{2 3 8 5 4 . 7 8}$ & 23861.58 \\
$70 \% \mathrm{P}_{\mathrm{G}, \max }$ & $\mathbf{2 0 3 8 6 . 0 0}$ & 20396.39 \\
\hline
\end{tabular}

TABLE XI

ICA-PSO FOR CRETE'S POWER SYSTEM (19-GENERATING UNITS): RESULTS AND CONVERGENCE CHARACTERISTICS

\begin{tabular}{cccc}
\hline Generating units & Outputs (MW) & $\begin{array}{c}\text { Generating } \\
\text { units }\end{array}$ & $\begin{array}{c}\text { Outputs } \\
(\mathbf{M W})\end{array}$ \\
\hline 1 & 5.44 & 11 & 15.00 \\
2 & 15.00 & 12 & 15.00 \\
3 & 15.00 & 13 & 3.00 \\
4 & 25.00 & 14 & 18.80 \\
5 & 25.00 & 15 & 5.00 \\
6 & 25.00 & 16 & 30.27 \\
7 & 11.80 & 17 & 30.28 \\
8 & 11.80 & 18 & 62.50 \\
9 & 11.80 & 19 & 62.50 \\
10 & 11.80 & & \\
Load demand (MW) & & 400.00 & \\
Power loss (MW) & & 0.0 & \\
Minimum cost $(\boldsymbol{\epsilon} / \mathbf{h})$ & & 32015.42 & \\
Mean cost $(\boldsymbol{\epsilon} / \mathbf{h})$ & & 32029.93 & \\
Maximum cost $(\boldsymbol{\epsilon} / \mathbf{h})$ & & 32041.10 & \\
Number of iterations & & 429 & \\
CPU time / per & & 0.064 & \\
iteration (sec) & &
\end{tabular}

\section{F. Case 6}

In this application the Hellenic bulk power system has 32 -generating units. The maximum power capability is $P_{G, \max }=6313 \mathrm{MW}$. Total load demand of the system is 6300 MW (heavy load). Technical limits and the coefficients of cost functions for 32-generating units are given in Appendix B. The system is also constrained because generating unit 26 is fixed at $28.00 \mathrm{MW}$.

Table XII shows the best dispatch solution and the convergence characteristics of ICA-PSO.

\section{G. Case 7}

We finalize the results giving full details of ICA-PSO operation on a representative case study. In this case study, the power loss is considered and each one of the six-generating units has two prohibited operating zones. Total load demand of the system is $1263 \mathrm{MW}$. All correct data are given in [19]. In the literature there are many HOTs applications in this system [2], [5], [6], [8], [13], [15], [18], [19], [24].

Also in this case study, sensitivity analysis [27], [28] was performed with respect to the parameters: allowed $n_{\text {Allow }}$, emergency $n_{\text {Emer }}$ and failed $n_{\text {Fail }}$ limits in the number of iterations; chosen limits of search intervals for the particles in the normal $\left[\mathrm{Nr}_{\min , N}, \mathrm{Nr}_{\max , N}\right]$, intensive $\left[\mathrm{Nr}_{\min , I}, \mathrm{Nr}_{\max , I}\right]$
TABLE XII

ICA-PSO FOR 32-GENERATING UNITS OF HELLENIC BULK POWER SYSTEM: RESUlTS AND CONVERGENCE CHARACTERISTICS

\begin{tabular}{|c|c|c|c|}
\hline Generating units & Outputs (MW) & $\begin{array}{c}\text { Generating } \\
\text { units }\end{array}$ & $\begin{array}{c}\text { Outputs } \\
\text { (MW) }\end{array}$ \\
\hline 1 & 150.00 & 17 & 265.00 \\
\hline 2 & 180.00 & 18 & 265.00 \\
\hline 3 & 160.00 & 19 & 265.00 \\
\hline 4 & 120.00 & 20 & 265.00 \\
\hline 5 & 120.00 & 21 & 265.00 \\
\hline 6 & 120.00 & 22 & 60.00 \\
\hline 7 & 135.00 & 23 & 110.00 \\
\hline 8 & 270.00 & 24 & 110.00 \\
\hline 9 & 140.00 & 25 & 265.00 \\
\hline 10 & 127.00 & 26 & 28.00 \\
\hline 11 & 265.00 & 27 & 110.00 \\
\hline 12 & 265.00 & 28 & 110.00 \\
\hline 13 & 270.00 & 29 & 270.00 \\
\hline 14 & 330.00 & 30 & 270.00 \\
\hline 15 & 265.00 & 31 & 300.00 \\
\hline 16 & 265.00 & 32 & 160.00 \\
\hline Load demand (MW) & & 6300.00 & \\
\hline Power loss (MW) & & 0.0 & \\
\hline Minimum cost $(€ / h)$ & & 227582.29 & \\
\hline Mean cost $(€ / h)$ & & 227590.21 & \\
\hline Maximum cost $(\boldsymbol{\epsilon} / \mathbf{h})$ & & 227599.13 & \\
\hline Number of iterations & & 509 & \\
\hline $\begin{array}{l}\text { CPU time / per } \\
\text { iteration (sec) }\end{array}$ & & 0.19 & \\
\hline
\end{tabular}

and scrutiny $\left[\mathrm{Nr}_{\min , S}, \mathrm{Nr}_{\text {max }, S}\right]$ search areas; initial population size $N$; and cognitive parameter $c$. Specifically, the following empirical 4-tuples of stochastic parameters were considered in the simulation results:

$$
\begin{aligned}
& n_{\text {Allow }}=\{5,10,15,20\} \\
& n_{\text {Emer }}=\{20,25,30,35\} \\
& n_{\text {Fail }}=\{35,40,45,50\} \\
& {\left[\mathrm{Nr}_{\min , N}, \mathrm{Nr}_{\text {max }, N}\right]=\left\{\begin{array}{c}
{[10,50],[15,250]} \\
{[15,500],[20,500]}
\end{array}\right\}} \\
& {\left[\mathrm{Nr}_{\min , I}, \mathrm{Nr}_{\text {max }, I}\right]=\left\{\begin{array}{c}
{[10,150],[50,1700]} \\
{[500,1500],[1200,1700]}
\end{array}\right\}} \\
& {\left[\mathrm{Nr}_{\min , S}, \mathrm{Nr}_{\text {max }, S}\right]=\left\{\begin{array}{c}
{[150,250],[1500,2500]} \\
{[2500,3500],[4000,5000]}
\end{array}\right\}} \\
& N=\{20,40,70,100\} \\
& c=\{0.5,1.0,2.0,2.5\} \text {. }
\end{aligned}
$$

The chosen values were evaluated by minimum of objective function (6) which was calculated with up to 1000 iterations in 100 trials. Due to the space limitation, the simulation results are omitted. They need few large matrices to be presented. The results reveal that the appropriate values for stochastic parameters are those given in the last column of Table I. Alternatively, the determination of optimum parameters of ICA-PSO can be achieved by incorporating any of the modern evolutionary algorithms such as cultural algorithms [29] in the ICA-PSO. This will be studied in a future research on stochastic optimization techniques. 
TABLE XIII

RESUlTS OF ICA-PSO FOR SIX-GENERATING UNITS WITH PROHIBITED OPERATING ZONES CONSIDERING OF POWER LOSS

\begin{tabular}{cc}
\hline Generating units & Outputs (MW) \\
\hline 1 & 447.09 \\
2 & 173.15 \\
3 & 263.90 \\
4 & 139.05 \\
5 & 165.63 \\
6 & 86.64 \\
Load demand (MW) & 1263.0 \\
Power loss (MW) & 12.47 \\
Minimum cost (\$/h) & $\mathbf{1 5 4 4 3 . 2 4}$ \\
Mean cost (\$/h) & 15443.97 \\
Maximum cost (\$/h) & 15444.33 \\
\hline
\end{tabular}

TABLE XIV

RESULTS OBTAINED BY DIFFERENT METHODS ON SIX-GENERATING UNITS System With Prohibited OPERATING ZONES CONSIDERING POWER LosS

\begin{tabular}{ccccc}
\hline Method & $\begin{array}{c}\text { Minimum } \\
\text { cost } \mathbf{( \$ / h )}\end{array}$ & $\begin{array}{c}\text { Total } \\
\text { Power } \\
\text { (MW) }\end{array}$ & $\begin{array}{c}\text { Power } \\
\text { loss }(\mathbf{M W})\end{array}$ & $\begin{array}{c}\text { Power } \\
\text { balance } \\
\text { (MW) }\end{array}$ \\
\hline ICA-PSO & $\mathbf{1 5 4 4 3 . 2 4}$ & 1275.46 & 12.47 & -0.01 \\
SA-PSO & 15447.0 & 1275.7 & 12.733 & -0.033 \\
BF-NM* & 15443.8164 & 1275.4 & 12.4437 & -0.0437 \\
APSO & 15443.5751 & 1275.3764 & 12.421628 & -0.04522 \\
DE & 15449.76 & 1275.947 & 12.957 & -0.01 \\
AIS & 15448.0 & 1275.655 & 12.655 & 0.0 \\
NPSO-LRS & 15450.5 & 1275.94 & 12.9361 & -0.0039 \\
ESO** & 15407.527 & 1272.46 & 12.824 & -3.374 \\
PSO & 15454 & 1276.01 & 12.9584 & -0.0516 \\
\hline
\end{tabular}

* Prohibited operating zone of generating unit- 6 is violated

** Infeasible solution (power balance violation)

Table XIII shows the best dispatch solution of ICA-PSO. It shows the mean and maximum cost, too. The results obtained by ICA-PSO are compared with those available from the literature in Table XIV, which shows that the performance of the ICA-PSO exceeds all other feasible solutions.

Fig. 1 shows the convergence of ICA-PSO in the best case of generation dispatch. The ICA-PSO converges after only 101 iterations (best iteration number $=101$ ).

Table XV represents the performance of ICA-PSO on the best case. Specifically, it gives the intensity of search for the particles iteration by iteration as a function of the global best achievement. It shows clearly how the population size is increased and the number of search intervals of the particles is oscillated adaptively. The rhythm of search the space for the best solution is similar to radio-emission frequency of pulsars (see Fig. 1). The critical numbers of iterations during the convergence process are also shown in Fig. 1. It is demonstrated the fast convergence capability of the coordinately aggregated particles in finding a high quality solution.

\section{H. Advantages of ICA-PSO Over Other HOTs}

Observing the comparison results given in Tables II, IV, VI, VIII, X, and XIV, the ICA-PSO algorithm is shown to be more efficient than all other HOTs except a quantum evolutionary algorithm (RQEA [11]) in one case, in finding optimal solutions.

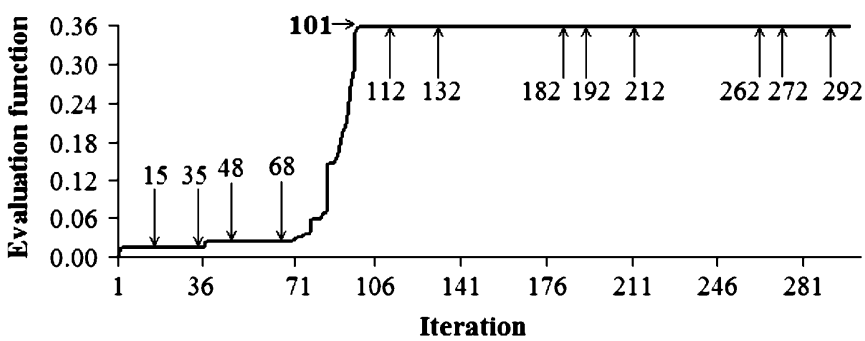

Fig. 1. ICA-PSO convergence for six-generating unit system with prohibited operating zones considering power loss (best dispatch solution).

TABLE XV

ICA-PSO OPERATION (BEST CASE) ON SIX-GENERATING UNITS SYSTEM WiTH PROHIBITED OPERATING ZONES CONSIDERING POWER LOSS

\begin{tabular}{ccccc}
\hline Iteration & $\begin{array}{c}\text { Global best } \\
\text { achievement }\end{array}$ & $\begin{array}{c}\text { Search } \\
\text { interval }\end{array}$ & $\begin{array}{c}\text { Search } \\
\text { intensity }\end{array}$ & $\begin{array}{c}\text { Population } \\
\text { size }\end{array}$ \\
\hline$[1,4]$ & Increased & {$[20,500]$} & Normal & 20 \\
{$[5,14]$} & Fixed & {$[20,500]$} & Normal & 20 \\
{$[15,34]$} & Fixed & {$[500,1500]$} & Intensive & 20 \\
{$[35,36]$} & Increased & {$[20,500]$} & Normal & 20 \\
{$[37,47]$} & Fixed & {$[20,500]$} & Normal & 20 \\
{$[48,67]$} & Fixed & {$[500,1500]$} & Intensive & 20 \\
{$[68,70]$} & Fixed & {$[1500,2500]$} & Scrutiny & 20 \\
{$[71, \mathbf{1 0 1}]$} & Increased & {$[20,500]$} & Normal & 20 \\
{$[102,111]$} & Fixed & {$[20,500]$} & Normal & 20 \\
{$[112,131]$} & Fixed & {$[500,1500]$} & Intensive & 20 \\
{$[132,181]$} & Fixed & {$[1500,2500]$} & Scrutiny & 20 \\
{$[182,191]$} & Fixed & {$[20,500]$} & Normal & 23 \\
{$[192,211]$} & Fixed & {$[500,1500]$} & Intensive & 23 \\
{$[212,261]$} & Fixed & {$[1500,2500]$} & Scrutiny & 23 \\
{$[262,271]$} & Fixed & {$[20,500]$} & Normal & 26 \\
{$[272,291]$} & Fixed & {$[500,1500]$} & Intensive & 26 \\
{$[292,341]$} & Fixed & {$[1500,2500]$} & Scrutiny & 26 \\
{$[342,351]$} & Fixed & {$[20,500]$} & Normal & 29 \\
{$[352,371]$} & Fixed & {$[500,1500]$} & Intensive & 29 \\
{$[372,421]$} & Fixed & {$[1500,2500]$} & Scrutiny & 29 \\
{$[422,431]$} & Fixed & {$[20,500]$} & Normal & 32 \\
{$[432,451]$} & Fixed & {$[500,1500]$} & Intensive & 32 \\
{$[452,501]$} & Fixed & {$[1500,2500]$} & Scrutiny & 32 \\
{$[502,511]$} & Fixed & {$[20,500]$} & Normal & 35 \\
{$[512,531]$} & Fixed & {$[500,1500]$} & Intensive & 35 \\
{$[532,581]$} & Fixed & {$[1500,2500]$} & Scrutiny & 35 \\
{$[582,591]$} & Fixed & {$[20,500]$} & Normal & 38 \\
{$[592,511]$} & Fixed & {$[500,1500]$} & Intensive & 38 \\
{$[512,561]$} & Fixed & {$[1500,2500]$} & Scrutiny & 38 \\
{$[562,1000]$} & Fixed & {$[1500,2500]$} & Scrutiny & 38 \\
\hline & & & & \\
& & & & \\
\hline & & & & \\
& & & & \\
& & &
\end{tabular}

Regarding ICA-PSO, it has an excellent performance in finding the global best solution in a comparable computing time over other HOTs because of the following main advantages.

1) It optimally manipulates the swarm with an adapted search rhythm similar to pulsars radio-emission one, namely the adaptively selected number of search intervals for the particles (10). Also the swarm is renewed by the introduced concept of variable population size (see Step 8 of ICA-PSO algorithm).

2) It manipulates well the violated particles and penalized them, but simultaneously giving them more search opportunities (see Step 6 of ICA-PSO algorithm).

3) It takes into account much more coordinators for the swarm's manipulation than the other PSO (see Step 2 of ICA-PSO algorithm). To be specific, the other PSO considers only two coordinators, namely the best position a particle it has ever encountered and the global/local best in the swarm. 
TABLE XVI

TECHNICAL LIMITS AND COEFFICIENTS OF THE CUBIC COST FunCtions OF THE 19-GENERATING UNITS OF AUTONOMOUS POWER SYSTEM OF CRETE

\begin{tabular}{cccccccc}
\hline Unit & $\mathbf{P}_{\min }$ & $\mathbf{P}_{\max }$ & $\boldsymbol{d}$ & $\boldsymbol{c}$ & $\boldsymbol{b}$ & $\boldsymbol{a}$ & $\begin{array}{c}\text { Fuel } \\
\text { cost }\end{array}$ \\
\hline 1 & 4.0 & 6.2 & 17.377 & -167.2 & 727.6 & 0.001 & 0.173 \\
2 & 7.0 & 15.0 & 0.476 & -11.824 & 378.937 & 0.001 & 0.173 \\
3 & 7.0 & 15.0 & 0.476 & -11.824 & 378.937 & 0.001 & 0.173 \\
4 & 13.0 & 25.0 & 0.18 & -8.053 & 355.088 & 0.001 & 0.173 \\
5 & 14.0 & 25.0 & 0.092 & -4.166 & 300.58 & 0.001 & 0.173 \\
6 & 14.0 & 25.0 & 0.092 & -4.166 & 300.58 & 0.001 & 0.173 \\
7 & 3.0 & 11.8 & 0.421 & -8.378 & 230.369 & 0.001 & 0.173 \\
8 & 3.0 & 11.8 & 0.421 & -8.378 & 230.369 & 0.001 & 0.173 \\
9 & 3.0 & 11.8 & 0.421 & -8.378 & 230.369 & 0.001 & 0.173 \\
10 & 3.0 & 11.8 & 0.421 & -8.378 & 230.369 & 0.001 & 0.173 \\
11 & 3.0 & 15.0 & 3.299 & -102.551 & 1024.0 & 90.0 & 0.3366 \\
12 & 3.0 & 15.0 & 3.299 & -102.551 & 1024.0 & 90.0 & 0.3366 \\
13 & 3.0 & 14.0 & 0.0 & 0.008 & 267.0 & 2113.0 & 0.3366 \\
14 & 3.0 & 18.8 & 0.0 & 0.008 & 219.0 & 2865.0 & 0.3366 \\
15 & 5.0 & 28.1 & 0.0 & 0.008 & 275.0 & 3757.0 & 0.3366 \\
16 & 2.4 & 58.0 & 0.001 & 0.01 & 227.0 & 5000.0 & 0.3366 \\
17 & 2.5 & 58.0 & 0.001 & 0.01 & 227.0 & 5000.0 & 0.3366 \\
18 & 11.2 & 62.5 & 0.001 & 0.01 & 145.54 & 5120.0 & 0.3366 \\
19 & 12.0 & 62.5 & 0.001 & 0.01 & 145.64 & 5120.0 & 0.3366 \\
\hline & & & & & & &
\end{tabular}

4) It adopts a stochastic coordination for the manipulation of best particles giving them full freedom (see Step 3 of ICA-PSO algorithm).

5) In the programming code of ICA-PSO algorithm the particles search the decision space only with accuracy of two decimal points. So, swarm does not exhaust its capability of "walking around." This technique is well supported by previous mentioned advantages.

These advantages provide the ICA-PSO more possibilities than the other HOTs, in exploring the decision space around local minima and escaping from them.

\section{CONCLUSION}

This paper proposed a new type of PSO algorithm, the ICA-PSO based on the cognitive and coordinated aggregation operators. It also introduced the variable population size, adaptive number of search intervals for the particles and search accuracy of particles up to two digit points, resulting in the improved convergence of the process. The ICA-PSO as well as the state-of-the-art HOTs competed in the optimization of ELD problem considering a number of different types of constrains. The results obtained in the systems with $6,13,15$, and 40 generating units, the island power system of Crete and the Hellenic bulk power system with various loads indicated an improved performance of the ICA-PSO over other HOTs, and good convergence characteristics.

\section{APPENDIX A}

The technical limits and coefficients of the cubic cost functions of the 19-generating units of autonomous power system of Crete are shown in Table XVI.
TABLE XVII

TECHNICAL LIMITS AND COEFFICIENTS OF LINEAR COST FUNCTIONS OF THE 32-GENERATING UNITS (CPPP) OF HELLENIC BULK SYSTEM

\begin{tabular}{|c|c|c|c|c|c|}
\hline Unit & $\mathbf{P}_{\min }$ & $\mathbf{P}_{\max }$ & $b$ & $a$ & $\begin{array}{l}\text { Fuel } \\
\text { cost }\end{array}$ \\
\hline 1 & 90.0 & 150.0 & 340.0 & 3560.0 & 0.18 \\
\hline 2 & 100.0 & 180.0 & 335.0 & 4307.0 & 0.18 \\
\hline 3 & 100.0 & 160.0 & 320.0 & 3856.0 & 0.18 \\
\hline 4 & 30.0 & 120.0 & 320.0 & 3856.0 & 0.18 \\
\hline 5 & 30.0 & 120.0 & 325.0 & 3856.0 & 0.18 \\
\hline 6 & 30.0 & 120.0 & 324.4 & 3806.0 & 0.18 \\
\hline 7 & 65.0 & 135.0 & 336.0 & 1232.5 & 0.18 \\
\hline 8 & 180.0 & 270.0 & 330.0 & 2422.5 & 0.18 \\
\hline 9 & 80.0 & 140.0 & 335.0 & 1232.5 & 0.204 \\
\hline 10 & 80.0 & 140.0 & 335.5 & 1232.5 & 0.204 \\
\hline 11 & 170.0 & 265.0 & 1195.49 & 16560.0 & 0.02 \\
\hline 12 & 170.0 & 265.0 & 1189.27 & 16560.0 & 0.02 \\
\hline 13 & 170.0 & 270.0 & 1215.14 & 17100.0 & 0.02 \\
\hline 14 & 200.0 & 330.0 & 1204.12 & 17100.0 & 0.02 \\
\hline 15 & 170.0 & 265.0 & 1150.46 & 20100.0 & 0.02 \\
\hline 16 & 170.0 & 265.0 & 1306.66 & 16560.0 & 0.02 \\
\hline 17 & 170.0 & 265.0 & 1299.95 & 16560.0 & 0.02 \\
\hline 18 & 170.0 & 265.0 & 1194.54 & 16560.0 & 0.02 \\
\hline 19 & 170.0 & 265.0 & 1203.64 & 16560.0 & 0.02 \\
\hline 20 & 170.0 & 265.0 & 1151.89 & 16560.0 & 0.02 \\
\hline 21 & 170.0 & 265.0 & 1212.27 & 16560.0 & 0.02 \\
\hline 22 & 40.0 & 60.0 & 1382.85 & 3900.0 & 0.02 \\
\hline 23 & 80.0 & 110.0 & 1355.06 & 7020.0 & 0.02 \\
\hline 24 & 80.0 & 110.0 & 1266.89 & 7020.0 & 0.02 \\
\hline 25 & 170.0 & 265.0 & 1231.14 & 16560.0 & 0.02 \\
\hline 26 & 28.0 & 28.0 & 1580.74 & 1800.0 & 0.02 \\
\hline 27 & 80.0 & 110.0 & 1312.41 & 6780.0 & 0.02 \\
\hline 28 & 80.0 & 110.0 & 1317.68 & 6780.0 & 0.02 \\
\hline 29 & 180.0 & 270.0 & 1295.16 & 16200.0 & 0.02 \\
\hline 30 & 180.0 & 270.0 & 1303.79 & 16200.0 & 0.02 \\
\hline 31 & 125.0 & 300.0 & 1150.23 & 19800.0 & 0.02 \\
\hline 32 & 42.0 & 160.0 & 324.0 & 3532.0 & 0.18 \\
\hline
\end{tabular}

The units of coefficients in Appendix A and B are: $\mathrm{P}_{\max }$ and $\mathrm{P}_{\min }$ in MV in $\mathrm{Kg}$-lt//MWh $; c$ in $\mathrm{Kg}$-lt/ $/ \mathrm{MWh}^{2} ; b$ in Kg-lt/MWh; $a$ in $\mathrm{Kg}$-lt, and fuel $\cos$ $€ / \mathrm{Kg}-\mathrm{lt}$

\section{APPENDIX B}

The technical limits and coefficients of linear cost functions of the 32-generating units (CPPP) of Hellenic bulk system are shown in Table XVII.

\section{REFERENCES}

[1] Modern Heuristic Optimization Techniques: Theory and Applications to Power Systems, K. Y. Lee and M. A. El-Sharkawi, Eds.. Hoboken, NJ: Wiley-IEEE Press, 2008.

[2] C. C. Kuo, "A novel coding scheme for practical economic dispatch by modified particle swarm approach," IEEE Trans. Power Syst., vol. 23, no. 4, pp. 1825-1835, Nov. 2008.

[3] L. D. S. Coelho and V. C. Mariani, "Particle swarm approach based on quantum mechanics and harmonic oscillator potential well for economic load dispatch with valve-point effects," Energy Convers. Manage., vol. 49, no. 11, pp. 3080-3085, 2008. 
[4] K. T. Chaturvedi, M. Pandit, and L. Srivastava, "Self-organizing hierarchical particle swarm optimization for nonconvex economic dispatch," IEEE Trans. Power Syst., vol. 23, no. 3, pp. 1079-1087, Aug. 2008.

[5] B. K. Panigrahi and V. R. Pandi, "Bacterial foraging optimisation: Nelder-Mead hybrid algorithm for economic load dispatch," IET Gen., Transm., Distrib., vol. 2, no. 4, pp. 556-565, 2008.

[6] B. K. Panigrahi, V. R. Pandi, and S. Das, "Adaptive particle swarm optimization approach for static and dynamic economic load dispatch," Energy Convers. Manage., vol. 49, no. 6, pp. 1407-1415, 2008.

[7] D.-K. He, F.-L. Wang, and Z.-Z. Mao, "Hybrid genetic algorithm for economic dispatch with valve-point effect," Elect. Power Syst. Res., vol. 78, no. 4, pp. 626-633, 2008.

[8] N. Nomana and H. Iba, "Differential evolution for economic load dispatch problems," Elect. Power Syst. Res., vol. 78, no. 3, pp. 1322-1331, 2008.

[9] L. D. S. Coelho and C.-S. Lee, "Solving economic load dispatch problems in power systems using chaotic and Gaussian particle swarm optimization approaches," Int. J. Elect. Power Energy Syst., vol. 30, no. 4, pp. 297-307, 2008.

[10] T. Adhinarayanan and M. Sydulu, "A directional search genetic algorithm to the economic dispatch problem with prohibited operating zones," in Proc. IEEE/PES Transmission and Distribution Conf. Expo., Chicago, IL, Apr. 21-24, 2008, pp. 1-5.

[11] G. S. S. Babu, D. B. Das, and C. Patvardhan, "Real-parameter quantum evolutionary algorithm for economic load dispatch," IET Gen., Transm., Distrib., vol. 2, no. 1, pp. 22-31, 2008.

[12] S.-K. Wang, J.-P. Chiou, and C.-W. Liu, "Non-smooth/non-convex economic dispatch by a novel hybrid differential evolution algorithm," IET Gen., Transm., Distrib., vol. 1, no. 5, pp. 793-803, 2007.

[13] B. K. Panigrahi, S. R. Yadav, S. Agrawal, and M. K. Tiwari, "A clonal algorithm to solve economic load dispatch," Elect. Power Syst. Res., vol. 77, no. 10, pp. 1381-1389, 2007.

[14] J.-P. Chiou, "Variable scaling hybrid differential evolution for largescale economic dispatch problems," Elect. Power Syst. Res., vol. 77, no. 1, pp. 212-218, 2007.

[15] A. I. Selvakumar and K. Thanushkodi, "A new particle swarm optimization solution to nonconvex economic dispatch problems," IEEE Trans. Power Syst., vol. 22, no. 1, pp. 42-51, Feb. 2007.

[16] C.-L. Chiang, "Genetic-based algorithm for power economic load dispatch," IET Gen., Transm., Distrib., vol. 1, no. 2, pp. 261-269, 2007.

[17] L. D. S. Coelho and V. C. Mariani, "Correction to "combining of chaotic differential evolution and quadratic programming for economic dispatch optimization with valve-point effect,"," IEEE Trans. Power Syst., vol. 21, no. 3, pp. 1465-1465, Aug. 2006.

[18] A. Pereira-Neto, C. Unsihuay, and O. R. Saavedra, "Efficient evolutionary strategy optimization procedure to solve the nonconvex economic dispatch problem with generator constraints," Proc. Inst. Elect. Eng., Gen., Transm., Distrib., vol. 152, no. 5, pp. 653-660, Sep. 2005.

[19] A. Pereira-Neto, C. Unsihuay, and O. R. Saavedra, "Reply concerning the comments on "Efficient evolutionary strategy optimization procedure to solve the nonconvex economic dispatch problem with generator constraints"," IET Gen., Transm., Distrib., vol. 1, no. 2, pp. 366-367, 2007.

[20] D. Liu and Y. Cai, "Taguchi method for solving the economic dispatch problem with nonsmooth cost functions," IEEE Trans. Power Syst., vol. 20, no. 4, pp. 2006-2014, Nov. 2005.

[21] J.-B. Park, K.-S. Lee, J.-R. Shin, and K. Y. Lee, "A particle swarm optimization for economic dispatch with nonsmooth cost functions," IEEE Trans. Power Syst., vol. 20, no. 1, pp. 34-42, Feb. 2005.

[22] R. GnanadassP. VenkateshN. P. Padhy, "Evolutionary programming based optimal power flow for units with non-smooth fuel cost functions," Elect. Power Compon. Syst., vol. 33, pp. 349-361, 2005.
[23] T. Aruldoss, A. Victoire, and A. E. Jeyakumar, "Hybrid PSO-SQP for economic dispatch with valve-point effect," Elect. Power Syst. Res., vol. 71, no. 1, pp. 51-59, 2004.

[24] Z.-L. Gaing, "Particle swarm optimization to solving the economic dispatch considering the generator constraints," IEEE Trans. Power Syst., vol. 18, no. 3, pp. 1187-1195, Aug. 2003.

[25] I. G. Damousis, A. G. Bakirtzis, and P. S. Dokopoulos, "Network-constrained economic dispatch using real-coded genetic algorithm," IEEE Trans. Power Syst., vol. 18, no. 1, pp. 198-205, Feb. 2003.

[26] N. Sinha, R. Chakrabarti, and P. K. Chattopadhyay, "Evolutionary programming techniques for economic load dispatch," IEEE Trans. Evol. Comp., vol. 7, no. 1, pp. 83-94, Feb. 2003.

[27] J. G. Vlachogiannis and K. Y. Lee, "A comparative study on particle swarm optimization for optimal steady-state performance of power systems," IEEE Trans. Power Syst., vol. 21, no. 4, pp. 1718-1728, Nov. 2006.

[28] J. G. Vlachogiannis and K. Y. Lee, "Contribution of generation to transmission system using parallel vector evaluated particle swarm optimization," IEEE Trans. Power Syst., vol. 20, no. 4, pp. 1765-1774, Nov. 2005

[29] B. Franklin and M. Bergerman, "Cultural algorithms: Concepts and experiments," in Proc. 2000 Congr. Evolutionary Computation, pp. $1245-1251$.

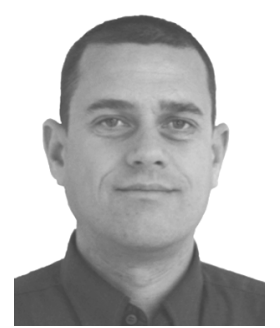

John G. Vlachogiannis received the B.Sc. in electrical engineering and the Ph.D. degree from the Aristotle University of Thessaloniki, Thessaloniki, Greece, in 1990 and 1994, respectively.

$\mathrm{He}$ is an Associate Professor at the Department of Electrical Engineering of the Technical University of Denmark (DTU), Kgs. Lyngby. Also he has joined with the Research Centre for Electric Technology (CET) of DTU. His research interests include control and management strategies and artificial intelligence techniques in planning and operation of power and

industrial systems

Dr. Vlachogiannis is a member of the Greek Computer Society (Member of IFIP, CEPIS) and member of the Technical Chamber of Greece.

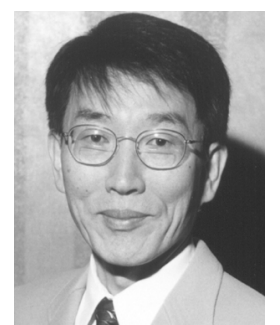

Kwang Y. Lee (LF'08) received the B.S. degree in electrical engineering from Seoul National University, Seoul, Korea, in 1964, the M.S. degree in electrical engineering from North Dakota State University, Fargo, in 1968, and the Ph.D. degree in system science from Michigan State University, East Lansing, in 1971.

He has been with Michigan State, Oregon State, the University of Houston, the Pennsylvania State University, and Baylor University, where he is now a Professor and Chairman of Electrical and Computer Engineering and Director of Power and Energy Systems Laboratory. His interests include power system control, operation, planning, and computational intelligence for power systems and power plant control.

Dr. Lee is a former Associate Editor of IEEE TRANSACTIONS ON NEURAL NETWORKS and Editor of IEEE TRANSACTIONS ON ENERGY CONVERSION. He is also a registered Professional Engineer. 